\title{
In-vitro Characterization of Silk Sericin as an Anti-aging Agent
}

\author{
Thitinan Kitisin ${ }^{1}$, Pannamas Maneekan ${ }^{2} \&$ Natthanej Luplertlop ${ }^{3}$ \\ ${ }^{1}$ Department of Anatomy, Faculty of Science, Mahidol University, Bangkok, Thailand \\ ${ }^{2}$ Department of Tropical Hygiene, Faculty of Tropical Medicine, Mahidol University, Bangkok, Thailand \\ ${ }^{3}$ Department of Microbiology and Immunology, Faculty of Tropical Medicine, Mahidol University, Bangkok, \\ Thailand \\ Correspondence: Natthanej Luplertlop, Department of Microbiology and Immunology, Faculty of Tropical \\ Medicine, Mahidol University, Bangkok, Thailand. Tel: 66-894-807-337. E-mail: natthanej.lup@mahidol.ac.th
}

\author{
Received: November 27, 2012 Accepted: December 18, 2012 Online Published: February 5, 2013 \\ doi:10.5539/jas.v5n3p54 \\ URL: http://dx.doi.org/10.5539/jas.v5n3p54
}

\begin{abstract}
Silk sericin is a natural macromolecular protein derived from the silkworm, Bombyx mori. It is also a by-product of silk-making. From previous reports, many cosmeceuticals and other cosmetic products have been developed with silk sericin. This study aimed to investigate an anti-aging property of silk sericin by in-vitro characterization using fibroblast cell culture model. The results showed that silk sericin can stimulate collagen type I synthesis, suppress the regulation of nitrite, which nitrite may induces oxidative stress, and up-regulate the expression of b-cell lymphoma 2 (bcl-2) to inhibit cell apoptosis, without altering fibroblast growth kinetics or cellular ultrastructure. Sericin anti-aging properties were comparable to vitamin C, except for oxidative stress, where silk sericin was superior. The results suggested that silk sericin possesses anti-aging properties that could be usefully incorporated into high-quality cosmetics, cosmeceuticals, and food supplements.
\end{abstract}

Keywords: anti-aging, collagen type 1, fibroblast cells, sericin, silk protein

\section{Introduction}

Skin aging is influenced by two main factors: 1) intrinsic or chronological aging, and 2) extrinsic factors. Intrinsic factors are commonly related to hormonal changes, metabolic processes (generation of reactive chemical compounds, such as activated oxygen species, sugars, and aldehydes), and telomeres (Rittié \& Fisher, 2002). The latter have come under increasing scrutiny and are believed to play a role in the intrinsic aging process at the cellular level. Extrinsic factors, or environmental exposure, are commonly related to ultraviolet (UV) irradiation, xenobiotics, and mechanical stress. The skin's aging process occurs throughout the epidermis, dermis, subcutaneous tissue, and the extracellular matrix (ECM), especially collagen, elastin fibers, and glycosaminoglycans (GAGs) (Baumann, 2007).

The human skin has direct contact with the environment and undergoes aging as a consequence of environmental damage by UV irradiation (Fisher et al., 2002). The sun damages the skin and accelerates the aging process. UV irradiation initiates molecular responses in human skin by the generation of reactive oxygen species (ROS) (Groß et al., 1999), activation of multiple cytokine and growth factor cell surface receptors, including epidermal growth factor receptor (EGF-R) (Varani et al., 2001), tumor necrosis factor- $\alpha$ receptor (TGF- $\alpha$ ) (Dy et al., 1999), and activating protein-1 (AP-1) (Angel et al., 2001). These regulate the expression of many genes involved in cellular growth and differentiation, and the transcription of several matrix metalloproteases (MMPs) family members (Fisher \& Voorhees, 1998), and also play some roles in negatively regulating type I procollagen transcription (Bornstein, 1996). Type I collagen is the most abundant protein in the skin connective tissues, which contain other types of collagen (III, V, and VII), elastin, proteoglycans, fibronectin, and other extracellular matrix proteins responsible for the strength and resiliency of the skin, and which affect skin texture and wrinkle formation (Bateman et al., 1996; Uitto, 1986).

Healthy skin degrades over time and various anti-aging products have been formulated to restore its condition, such as topical skin-care products, vitamins C \& E, co-enzyme Q10, ferulic acid, and natural products (Lupo, 2001). This study investigated one waste product from the silk industry, silk sericin, which is known to have moisturizing properties (Padamwar et al., 2005), protect against UV exposure and oxidation (Dash et al., 2008), form a protective film on the skin, hair, and nails (Dal-Pra et al., 2006; Zhang, 2002), aid in the wound-healing 
process (Aramwit \& Sangcakul, 2007), and protect against cell death (Takahashi et al., 2003). Many products use this protein for various applications in the textile industry, cosmetics and cosmeceutical products, and food supplements (Zhang, 2002). In this study, we aimed to investigate the properties of silk sericin, which might be related to collagen type I stimulation, anti-oxidation, and anti-apoptosis in in-vitro fibroblast cell culture model. The results from this research will provide important information to elucidate its potential in the production of health-related products.

\section{Materials and Methods}

\subsection{Cell Culture}

Late-passage fibroblast cell culture (passages 12-15) was used in all experiments. Cells from primary skin fibroblast were kindly provided by Dr. Kawin Leelawat, Department of General Surgery, Rajvithi Hospital, Bangkok, Thailand. The isolated fibroblasts were cultured in DMEM containing $10 \%$ FBS (v/v) with $1 \%(\mathrm{v} / \mathrm{v})$ antibiotics (Gibco, Carlsbad, CA) and were cultured until confluent. Treated condition was added with $1 \mathrm{ml}$ of $500 \mu \mathrm{g}$ silk sericin/ml (extracted from Bombyx mori by high temperature process of Lilawadee Herb Co., Ltd and Amornrat Promboon, Department of Biochemistry, Faculty of Science, Kasetsart University, Bangkok, Thailand), $100 \mu \mathrm{g}$ vitamin $\mathrm{C} / \mathrm{ml}$ and DMEM were placed into a 6-well tissue culture plate and kept attached throughout the culture period. Cells and culture supernatants were then used in subsequent experiments, and collected on days $1,3,5,7,9$, and 11. Cell culture supernatant was used in Western blot for collagen-type-1 detection and nitrite production assay. Treated and untreated cells were used in cell-growth kinetics, morphological analysis by SEM, and Western blot for bcl-2.

\subsection{Cytotoxicity Testing}

The vitamin C and silk sericin samples were placed in 24-well tissue culture plates. After incubation for $24 \mathrm{~h}$, the samples were removed. Kinetic cell proliferation was verified by Trypan blue dye exclusion assay. Cytotoxicity was then assessed by MTT (3-(4,5-dimethyl-thiazoyl)-2,5-diphenyl-SH-tetrazolium bromide) method (Edmondson et al., 1988). MTT solution was added at $20 \mu \mathrm{l}(0.05 \mathrm{~g}$ MTT/1 in PBS) of MTT to each well and the microplates incubated further at $37^{\circ} \mathrm{C}$ for $4 \mathrm{~h}$. Then, $100 \mu \mathrm{l}$ of acidified isopropanol $(0.04 \mathrm{~N} \mathrm{HCl}$ in isopropanol) were added to the cultures and mixed thoroughly. The solubilized reaction products were transferred to a 96 -well plate and absorbance values of each well determined by microplate enzyme-linked immunoassay (ELISA) reader with $540 \mathrm{~nm}$ filter. The survival rates of the controls were set to represent $100 \%$ viability. Untreated cultures were used as control.

\subsection{Western Blot}

Collagen type 1 synthesis in cell culture supernatant, bcl-2 and $\beta$-actin expression in fibroblast cells were determined using the SDS-PAGE protocol described by Missé et al. (2001). At each time point, the equal amounts of protein were electrophoresed under reducing conditions and transferred electrophoretically to nitrocellulose membranes. Membranes were incubated for $30 \mathrm{~min}$ in Tris buffered saline $(50 \mathrm{mM} \mathrm{NaCl}, 20 \mathrm{mM}$ Tris $\mathrm{HCl}, \mathrm{pH} 7.5)$ containing $5 \%(\mathrm{v} / \mathrm{v})$ bovine serum albumin (BSA) and $0.1 \%(\mathrm{v} / \mathrm{v})$ Tween 20 , then incubated overnight with rabbit anti-human antibodies to collagen type 1 (Santa Cruz, USA). Proteins were visualized by enhanced chemiluminescence system (Amersham Pharmacia Biotech, Piscataway, NJ). Following blot visualization, relative band density corresponding to collagen type $1(98 \mathrm{kDa}), \mathrm{bcl}-2(28 \mathrm{kDa})$ and $\beta$-actin $(47$ $\mathrm{kDa}$ ) were determined from light scans of the resulting films using densitometric analysis, Gene Tools software (SynGene Laboratory, UK).

\subsection{Detection of MMP Activity}

The gelatinase activities of MMP-2 in cell-culture supernatant from both stimulated and control fibroblasts, were determined by SDS-PAGE zymography, as described by Missé et al. (2001). Then, $500 \mu 1$ of cell-culture supernatant were lyophilized, resuspended in loading buffer $(0.125 \mathrm{M}$ Tris- $\mathrm{HCl} \mathrm{pH} 6.8,4 \%$ SDS, and $0.04 \%$ bromophenol blue) without prior denaturation, and run on a 7.5\% SDS-polyacrylamide gel containing $1 \mathrm{mg}$ gelatin $/ \mathrm{ml}$. Gels were stained with Coomassie brilliant blue G-250 and destained in 30\% (v/v) methanol with $10 \%(\mathrm{v} / \mathrm{v})$ acetic acid to detect gelatinase activity. Proteolytic activity was identified as a clear band against a blue background and quantified by computerized image analysis through optical densitometry, using Gene Tools software (SynGene Laboratory, UK).

\subsection{ELISA for Type I Procollagen Protein}

Collagen type 1 was measured by ELISA, as described by Jenkins et al. (2007). Cells were fixed in 3.7\% formaldehyde for $10 \mathrm{~min}$ at room temperature, washed and permeabilized with $0.3 \%$ Triton X-100 in PBS for 10 min, then washed again. All were washed with $0.1 \%$ Tween 20 in PBS. A blocking agent $(2.5 \%(\mathrm{v} / \mathrm{v})$ BSA in 
$0.1 \%(\mathrm{v} / \mathrm{v})$ Tween 20/PBS) was added to each well and incubated for $1 \mathrm{~h}$ at room temperature (or overnight at $4{ }^{\circ} \mathrm{C}$ ) and then washed before adding the primary antibody. Cells were then incubated for $1 \mathrm{~h}$ at $37{ }^{\circ} \mathrm{C}$ with 50 $\mu \mathrm{l} /$ well of rabbit anti-rat collagen type 1 polyclonal antibody (1:500; Santa Cruz, USA), washed and then incubated for 1 hour at $37{ }^{\circ} \mathrm{C}$ with goat anti-rabbit IgG secondary antibody conjugated with horseradish peroxidase (1:5000; Santa Cruz, USA). Plates were washed and $200 \mu \mathrm{l}$ substrate solutions were made with Sigma FAST OPD (o-phenylenediamine dihydrochloride) tablets dissolved in $20 \mathrm{ml}$ of distilled water. The final concentrations were $0.4 \mathrm{mg} \mathrm{OPD} / \mathrm{ml}, 0.4 \mathrm{mg}$ urea hydrogen peroxide $/ \mathrm{ml}$ and $0.05 \mathrm{M}$ phosphate-citrate $(\mathrm{pH}$ 5.0). The enzyme reaction was stopped after $30 \mathrm{~min}$ (in the dark) by adding $50 \mu \mathrm{l}$ of $2 \mathrm{M} \mathrm{H}_{2} \mathrm{SO}_{4}$ to each well. The plates were then read at $450 \mathrm{~nm}$ with Magellan plate-reader software, on a multi-well plate reader (Sunrise, Tecan, Austria).

\subsection{Nitrite Production Assay}

Culture fluids were assayed by Griess reaction for nitrite, as described by Green et al. (1990). Fifty microliter aliquots of conditioned medium were incubated with $50 \mu \mathrm{l}$ of $1 \%$ sulfanilamide and $50 \mu \mathrm{l}$ of $1 \%$ $\mathrm{N}$-1-naphthylethylenediamine dihydrochloride in $2.5 \% \mathrm{H}_{3} \mathrm{PO}_{4}$ (Sigma) at room temperature for $5 \mathrm{~min}$. Optical density at $540 \mathrm{~nm}$ was measured. Nitrite was quantified against a $\mathrm{NaNO}_{2}$ standard.

\subsection{Preparation for Electron Microscopy}

The overall morphology and cell-cell interaction of the fibroblasts after being treated with vitamin $\mathrm{C}$ or silk sericin was assessed by SEM. Cells were rinsed, fixed for $1 \mathrm{~h}$ in $2.5 \%$ glutaraldehyde, washed for $5 \mathrm{~min}$ in $0.1 \mathrm{M}$ sodium-cacodylate buffer ( $\mathrm{pH}$ 7.4), dehydrated in a graded series of ethanol, and dried in a critical-point dryer. Specimens were sputter-coated with gold and examined with SEM (Hitachi, model S2360N, Japan).

\subsection{Statistical Analysis}

The analysis examined the difference among treated group (silk sericin), positive control group (vitamin C), and negative control group (media alone). All data were obtained from one independent experiment carried out in triplicate. Data were analyzed using the Intercooled Stata 9.0 (SN: 1990531881, StataCorp LP). One-way analysis of variance (ANOVA) among the three groups were calculated with collagen type 1 synthesis which confirmed by ELISA. Another test; anti-oxidation test, measured nitrite production with Griess reagent assay was analyzed by ANOVA. The level of significance for all tests was set at $p<0.05$.

\section{Results and Discussion}

\subsection{Cell Toxicity Test}

In vitro cell toxicity looking at $\mathrm{LD}_{50}$ concentration was $100 \mu \mathrm{g}$ vitamin $\mathrm{C} / \mathrm{ml}$ and $500 \mu \mathrm{g}$ silk sericin $/ \mathrm{ml}$.

\subsection{Fibroblast Growth}

Figure 1 showed the results of the fibroblast growth study for cell growth on media alone (negative control), vitamin C (positive control), and silk sericin. There was a gradual increased in cell concentration $\left(\log _{10} / \mathrm{ml}\right)$ from day0 to day3 in all 3 groups, but highest among the silk-sericin-treated cells. From day5, cell growth started to decline in all groups, with silk sericin showing the least reduction. This study showed that silk sericin helped to promote fibroblast growth as similar to Aramwit et al. (2009), which they indicated that silk sericin is non-toxic to fibroblasts cells and can promote the wound healing process.

All groups reached peak cell count on day3, discounting the potential presence of mitogenic activity induced either by silk sericin or vitamin C. This contradicts the findings of Terada et al. (2002) where sericin acted as a mitogenic factor in hybridoma cell lines.

Silk-sericin-treated cells remained at a plateau until day7, indicated the cell-preservative effect of silk sericin. These findings also differ from Tsubouchi et al. (2005) where the day 3 count for silk-sericin-treated fibroblasts was significantly enhanced, compared with the control. They attributed this to the acceleration of initial cell attachment. The differences in cell concentrations between the 3 groups on day 5 were statistically significant $(p$ $=0.046$ ).

\subsection{Stimulation and Inhibition Functions of Silk Sericin}

\subsubsection{Collagen Type 1 Synthesis}

Western blot assay (Figure 2) showed collagen synthesis with vitamin $\mathrm{C}$ and silk sericin trending consistently higher than media, most noticeably on day3. Both groups also showed continuous decline after day5, but silk sericin sustained slightly higher collagen type I concentrations until day11. Collagen synthesis was also indirectly confirmed by detecting MMP-2 activity, which characterized the signal for collagen synthesis 
stimulation, through gelatinolytic zymogram. This technique showed a similar trend as Western blot assay, but with less pronounced differences. The results were supported by Aramwit et al. (2009). Their report determined that methionine and cysteine content in silk sericin are important factors to promote cell growth and collagen synthesis.

Fibroblast Growth Kinetics

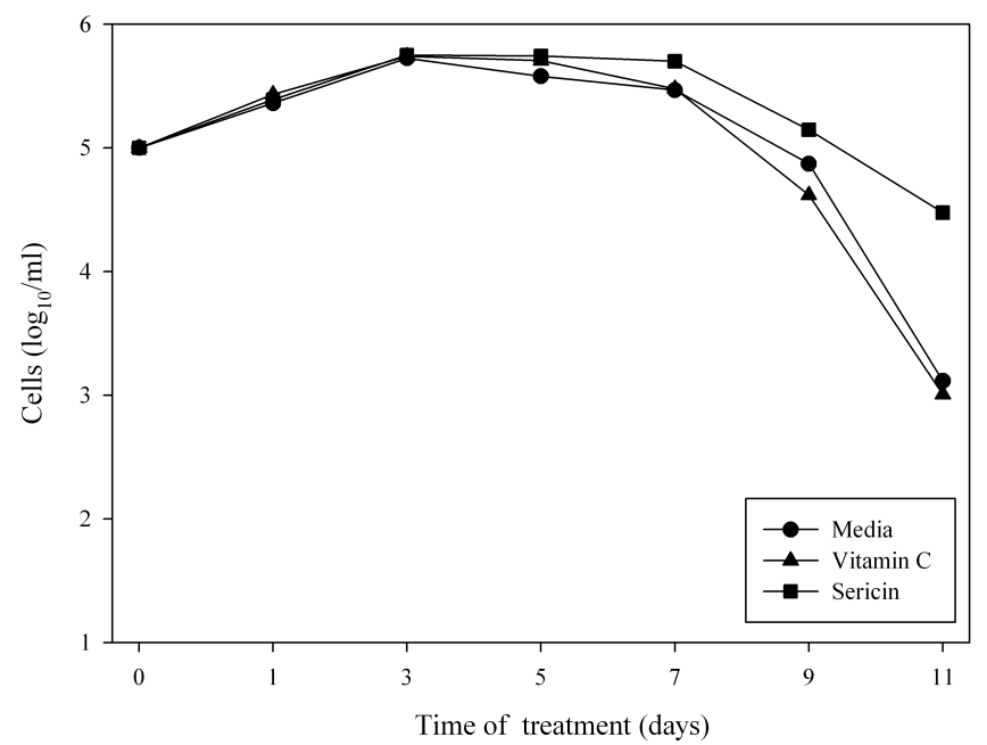

Figure 1. Fibroblast growth kinetics. Fibroblasts in media (negative control), treated with vitamin $\mathrm{C}$ (positive control), and silk sericin were incubated at days $0,1,3,5,7,9$, and 11 , with cell counts monitored at each point.

Silk sericin cells had the lowest rate of decrease, followed by vitamin $\mathrm{C}$, then media alone

Western Blotting for Detection of Collagen Type I Expression and SDS-PAGE Zymography of MMP-2

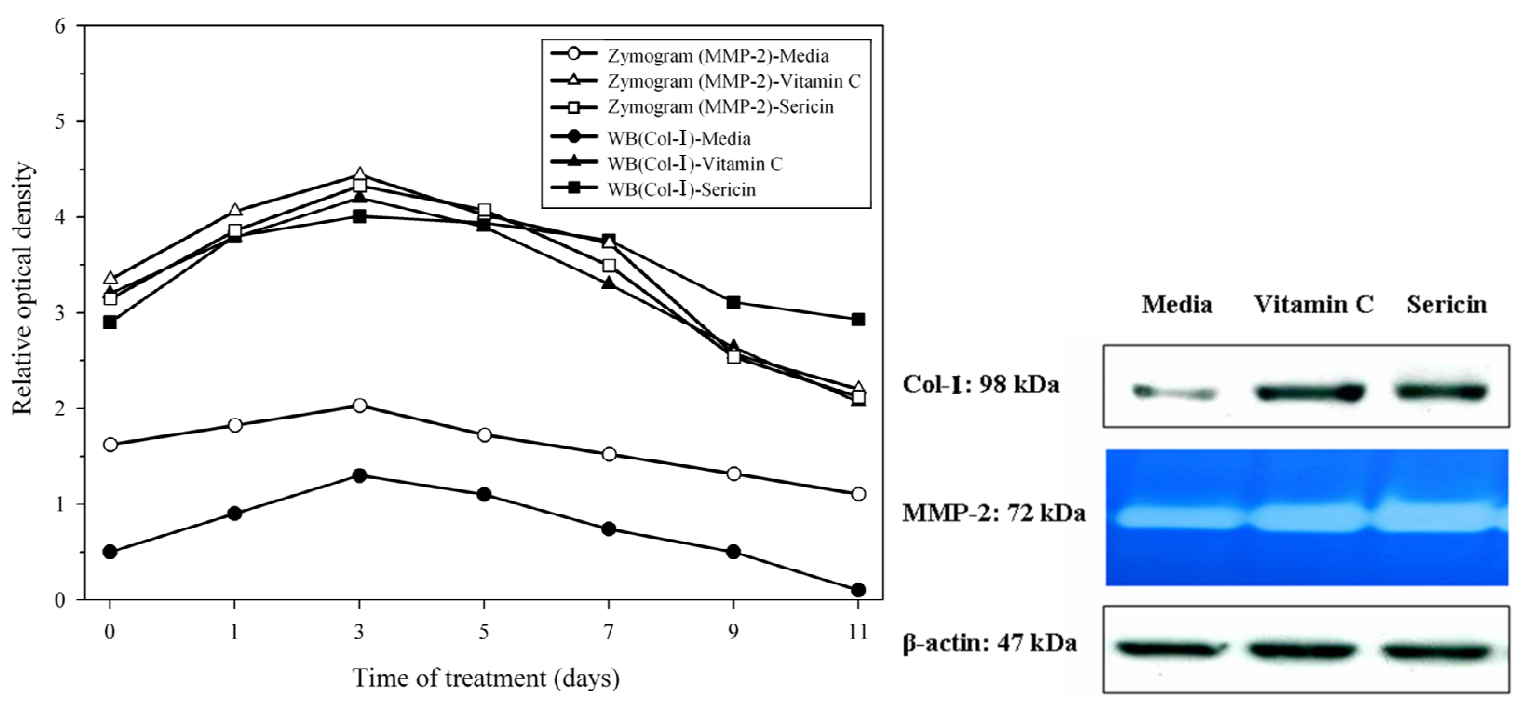

Figure 2. Western blot for detection of collagen type I expression and SDS-PAGE zymography of MMP-2 detection. Both of them showed the collagen expression increasing in silk sericin than vitamin $\mathrm{C}$, especially within three days and absolutely higher than media along 11 days 


\subsubsection{Collagen Type I Synthesis Confirmation}

ELISA showed that collagen type I peaked on day5 $(p<0.01)$. Figure 3 showed the amount of collagen type I in the silk sericin group was less than the vitamin $\mathrm{C}$ group from day1 to day3. On day5, the collagen type I in the vitamin $\mathrm{C}$ group started to decline sharply. The silk sericin group continued to increase until day5 and sustained consistently higher collagen type I concentration over vitamin $\mathrm{C}$ and media until day11.

The trend was similar to collagen detection by Western blot and ELISA, including peak concentration on day5 ( $p$ $=0.035$ ), as shown in Figure 2. These coincide with other studies where the addition of silk sericin enhanced growth in several human cell lines (Terada et al., 2002) and human skin fibroblast (Tsubouchi et al., 2005).

\section{ELISA Collagen Type I}

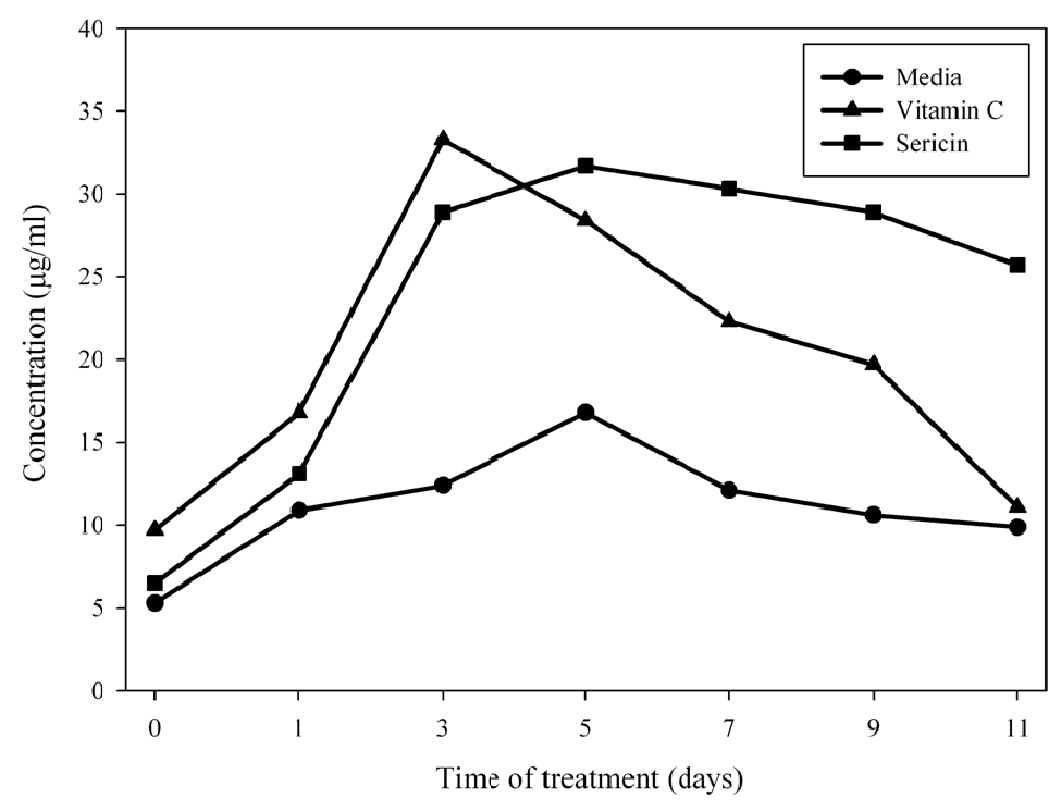

Figure 3. Collagen type I by ELISA. The test confirmed the presence of collagen synthesis. The silk sericin group had consistently higher levels from day 3 to day11

\subsubsection{Anti-Oxidation Test}

The anti-oxidative properties of silk sericin were determined by measuring nitrite production with Griess reagent assay. All groups showed comparable nitrite levels only on day1. Increasing trends for both media and vitamin C were evident from day 3 onwards. Silk sericin presented a totally different pattern, as it continued to suppress nitrite production (Figure 4); this highlights the anti-oxidizing effect of silk sericin. Nitrite concentration on day5 was statistically significant $(p=0.024)$, similar to the claims by Kato et al. (1998) that silk sericin suppressed in-vitro lipid peroxidation. Kato et al. (1998) indicated that silk sericin, which contained high amount of hydroxyl amino acids (serine and threonine) that might be responsible for the anti-oxidative function. Moreover, silk sericin was also shown to inhibit the tyrosinase activity and lipid peroxidation (Kato et al., 1998). 


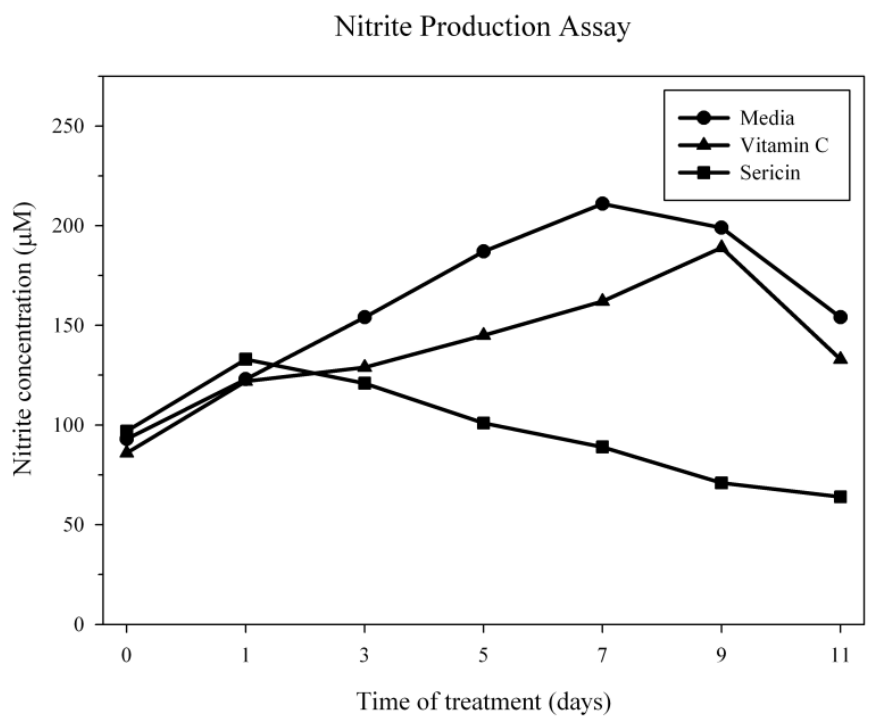

Figure 4. Determination of nitrite production by Griess reagent assay. Sericin showed a nitrite reduction, in contrast with vitamin $\mathrm{C}$ and media alone

\subsubsection{Cell Morphology}

The SEM images on day5 (Figure 5) revealed that silk sericin was morphologically superior to vitamin $\mathrm{C}$ and media, verified by well-extended fibrous shapes and lesser detachment from other cells (i.e. cell-cell interaction). This exhibited the cell-attachment potential of silk sericin in cultivation. Within the increasing of collagen type I synthesis by silk sericin treatment, the morphology of the fibroblast cell exhibited higher cell adhesives among treated group and control. The result indicated that silk sericin influences the matrix production by fibroblast. It was possible to suggest the roles of silk sericin on cellular matrix production for fibroblast as an anti-aging agent.

A

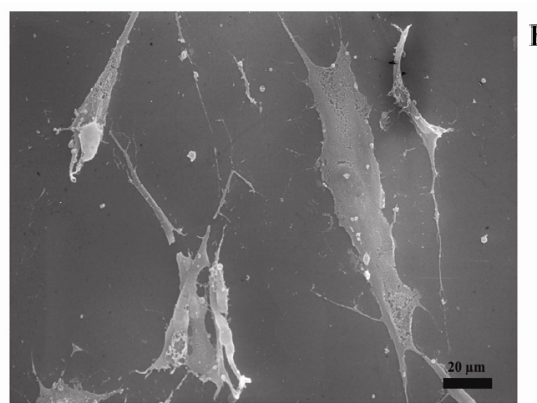

C

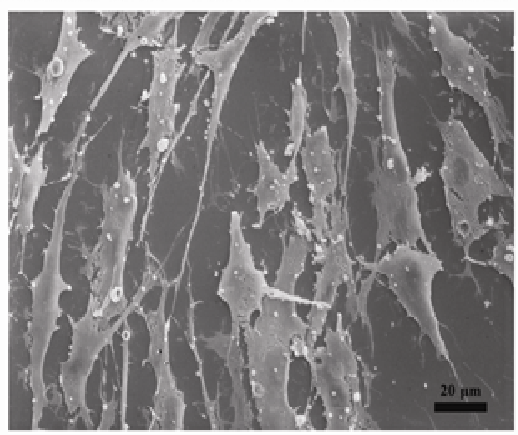

B

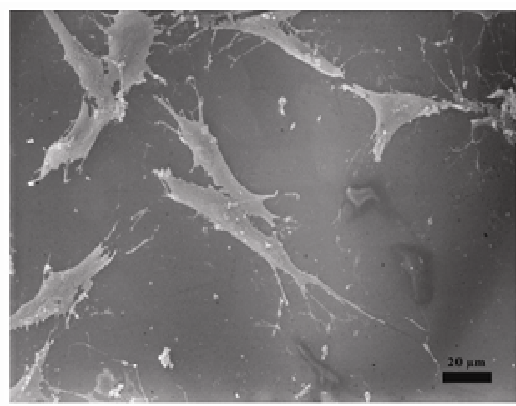

Figure 5. SEM images of fibroblast cells on day5. Media (A), vitamin C (B), and silk sericin (C). The cells in
silk sericin were more well extend Cell Shape and Matrix Production of Fibroblasts Cultured on Fibroin ed morphology than in vitamin $\mathrm{C}$ and in media 


\subsubsection{Anti-Apoptosis Test}

To measure cellular-level anti-aging properties, bcl-2 (an anti-apoptosis signal) was determined by using Western blotting. The results showed that silk sericin could stimulate the expression of bcl-2 to levels comparable to vitamin C (Figure 6). This supports the findings by Dash et al. (2008), that pre-treatment with silk sericin up-regulates the expression of bcl-2 leading to suppress bax (bcl-2-associated $\mathrm{x}$ protein) expression. The results suggested that silk sericin could be used as an anti-apoptotic agent, which it stimulated the bcl-2 by reducing the oxidative stress in fibroblast. This study showed the potential role of silk sericin as an anti-aging agent, which could be benefit to pharmaceutical and cosmeceutical industry.

Western Blotting Assay for bcl-2 Detection
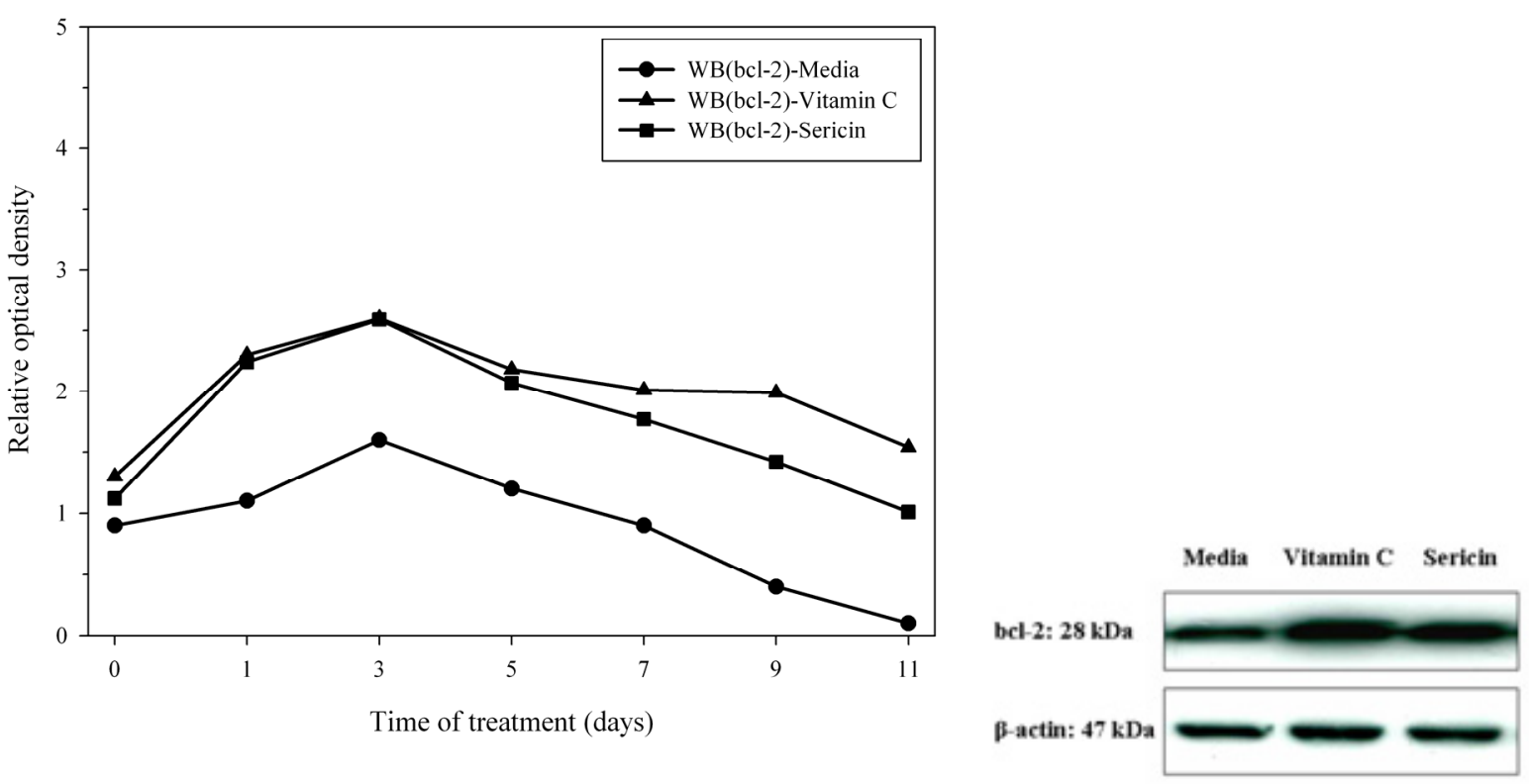

Figure 6. Western blot assay for bcl-2 detection. The bcl-2 expression in silk sericin was persistently intensified than vitamin $\mathrm{C}$ and media through 11 experimental days

\section{Conclusions}

This study showed that silk sericin possesses anti-aging properties, since it stimulates collagen synthesis and reduces apoptosis, like vitamin C. However, silk sericin surpassed vitamin C in limiting oxidative stress. The relationship between silk sericin, various cell-signaling pathways, and anti-aging apoptosis requires elucidation by further studies at the transcription and translation levels.

\section{Acknowledgements}

This study was supported by Trop. Med Grants (2011): Faculty of Tropical Medicine, Mahidol University and Thailand Research Fund, \#MRG 5380006.

\section{References}

Angel, P., Szabowski, A., \& Schorpp-Kistner, M. (2001). Function and regulation of AP-1 subunits in skin physiology and pathology. Oncogene, 20(19), 2413-2423. http://dx.doi.org/10.1038/sj.onc.1204380

Aramwit, P., Kanokpanont, S., De-Eknamkul, W., \& Srichana, T. (2009). Monitoring of inflammatory mediators induced by silk sericin. J. Biosci. Bioeng., 107(5), 556-561. http://dx.doi.org/10.1016/j.jbiosc.2008.12.012

Aramwit, P., Kanokpanont, S., De-Eknamkul, W., Kamei, K., \& Srichana, T. (2009). The effect of sericin with variable amino-acid content from different silk strains on the production of collagen and nitric oxide. $J$. Biomater. Sci. Polym. Ed., 20(9), 1295-1306. http://dx.doi.org/10.1163/156856209X453006

Aramwit, P., \& Sangcakul, A. (2007). The effects of sericin cream on wound healing in rats. Biosci. Biotechnol. Biochem., 71(10), 2473-2477. http://dx.doi.org/10.1271/bbb.70243 
Bateman, J. F., Lamandé, S. R., \& Ramshaw, J. A. M. (1996). Collagen superfamily. In W. D. Comper (Ed.), Extracellular Matrix (pp. 22-67). Amsterdam: The Netherlands: Harwood academic publishers.

Baumann, L. (2007). Skin ageing and its treatment. J. Pathol., 211, 241-251. http://dx.doi.org/10.1002/path.2098

Bornstein, P. (1996). Regulation of expression of the alpha 1 (I) collagen gene: a critical appraisal of the role of the first intron. Matrix Biol., 15(1), 3-10. http://dx.doi.org/10.1016/S0945-053X(96)90121-3

Dal-Pra, I., Chiarini, A., Boschi, A., Freddi, G., \& Armato, U. (2006). Novel dermo-epidermal equivalents on silk fibroin-based formic acid-crosslinked three-dimensional nonwoven devices with prospective applications in human tissue engineering/regeneration/repair. Int. J. Mol. Med., 18(2), 241-247.

Dash, R., Mandal, M., Ghosh, S. K., \& Kundu, S. C. (2008). Silk sericin protein of tropical tasar silkworm inhibits UVB-induced apoptosis in human skin keratinocytes. Mol. Cell Biochem., 311, 111-119. http://dx.doi.org/10.1007/s11010-008-9702-z

Dy, L. C., Pei, Y., \& Travers, J. B. (1999). Augmentation of ultraviolet B radiation-induced tumor necrosis factor production by the epidermal platelet-activating factor receptor. J. Biol. Chem., 274(38), 26917-26921. http://dx.doi.org/10.1074/jbc.274.38.26917

Edmondson, J. M., Armstrong, L. S., \& Martinez, A. O. (1988). A rapid and simple MTT based spectrophotometric assay for determination drug sensitivity in monolayer cultures. J. Tissue Cult. Methods, 11(1), 15-17. http://dx.doi.org/10.1007/BF01404408

Fisher, G. J., Kang, S., Varani, J., Bata-Csorgo, Z., Wan, Y., Datta, S., \& Voorhees, J. J. (2002). Mechanisms of Photoaging and Chronological Skin Aging. Arch. Dermatol., 138(11), 1462-1470. http://dx.doi.org/10-1001/pubs.Arch Dermatol.-ISSN-0003-987x-138-11-dre20020

Fisher, G. J., \& Voorhees, J. J. (1998). Molecular mechanisms of photoaging and its prevention by retinoic acid: ultraviolet irradiation induces MAP kinase signal transduction cascades that induce AP-1-regulated matrix metalloproteinases that degrade human skin in vivo. J. Investig. Dermatol. Symp. Proc., 3(1), 61-68.

Green, S. J., Crawford, R. M., Hockmeyer, J. T., Meltzer, M. S., \& Nacy, C. A. (1990). Leishmania major amastigotes initiate the L-arginine-dependent killing mechanism in IFN- $\gamma$ stimulated macrophages by induction of tumor necrosis factor- $\alpha$. J. Immunol., 145(12), 4290-4297.

Groß, S., Knebel, A., Tenev, T., Neininger, A., Gaestel, M., Herrlich, P., \& Böhmer, F. D. (1999). Inactivation of protein-tyrosine phosphatases as mechanism of UV-induced signal transduction. J. Biol. Chem., 274(37), 26378-26386. http://dx.doi.org/10.1074/jbc.274.37.26378

Jenkins, C., Milsted, A., Doane, K., Meszaros, G., Toot, J., \& Ely, D. (2007). A cell culture model using rat coronary artery adventitial fibroblasts to measure collagen production. BMC Cardiovasc. Disord., 7, 13-22. http://dx.doi.org/10.1186/1471-2261-7-13

Kato, N., Sato, S., Yamanaka, A., Yamada, H., Fuwa, N., \& Nomura, M. (1998). Silk protein, Sericin, inhibits lipid peroxidation and Trosinase activity. Biosci. Biotechnol. Biochem., 62(1), 145-147. http://dx.doi.org/10.1271/bbb.62.145

Lupo, M. P. (2001). Antioxidants and vitamins in cosmetics. Clin. Dermatol., 19(4), 467-473. http://dx.doi.org/10.1016/S0738-081X(01)00188-2

Missé, D., Esteve, P. O., Renneboog, B., Vidal, M., Cerutti, M., St. Pierre, Y., ... Veas, F. (2001). HIV-1 glycoprotein 120 induces the MMP-9 cytopathogenic factor production that is abolished by inhibition of the p38 mitogen-activated protein kinase signaling pathway. Blood, 98(3), 541-547. http://dx.doi.org/10.1182/blood.V98.3.541

Padamwar, M. N., Pawar, A. P., Daithankar, A. V., \& Mahadik, K. R. (2005). Silk sericin as a moisturizer: an in vivo study. J. Cosmet. Dermatol., 4(4), 250-257. http://dx.doi.org/10.1111/j.1473-2165.2005.00200.x

Rittié, L., \& Fisher, G. J. (2002). UV-light-induced signal cascades and skin aging. Ageing Res. Rev., 1, 705-720. http://dx.doi.org/10.1016/S1568-1637(02)00024-7

Takahashi, M., Tsujimoto, K., Yamada, H., Takagi, H., \& Nakamori, S. (2003). The silk protein, sericin, protects against cell death caused by acute serum deprivation in insect cell culture. Biotechnol. Lett., 25(21), 1805-1809. http://dx.doi.org/10.1023/A:1026284620236 
Terada, S., Nishimura, T., Sasaki, M., Yamada, H., \& Miki, M. (2002). Sericin, a protein derived from silkworms, accelerates the proliferation of several mammalian cell lines including a hybridoma. Cytotechnology, 40(1-3), 3-12. http://dx.doi.org/10.1023/A:1023993400608

Tsubouchi, K., Igarashi, Y., Takasu, Y., \& Yamada, H. (2005). Sericin enhances attachment of cultured human skin fibroblasts. Biosci. Biotechnol. Biochem., 69(2), 403-405. http://dx.doi.org/10.1271/bbb.69.403

Uitto, J. (1986). Connective tissue biochemistry of the aging dermis. Age-associated alterations in collagen and elastin. Dermatol. Clin., 4(3), 433-446.

Varani, J., Spearman, D., Perone, P., Fligiel, S. E. G., Datta, S., Wang, Z. Q., ... Voorhees, J. J. (2001). Inhibition of type I procollagen synthesis by damaged collagen in photoaged skin and by collagenase-degraded collagen in vitro. Am. J. Pathol., 158(3), 931-942. http://dx.doi.org/10.1016/S0002-9440(10)64040-0

Zhang, Y. Q. (2002). Applications of natural silk protein sericin in biomaterials. Biotechnol. Adv., 20(2), 91-100. http://dx.doi.org/10.1016/S0734-9750(02)00003-4 